Jakob Albrethsen*, Hanne Frederiksen, Anna-Maria Andersson, Ravinder Anand-Ivell, Loa Nordkap, Anne Kirstine Bang, Niels Jørgensen and Anders Juul

\title{
Development and validation of a mass spectrometry-based assay for quantification of insulin-like factor 3 in human serum
}

https://doi.org/10.1515/cclm-2018-0171

Received February 14, 2018; accepted May 3, 2018

\begin{abstract}
Background: The circulating level of the peptide hormone insulin-like factor 3 (INSL3) is a promising diagnostic marker reflecting Leydig cell function in the male. Few commercial immunoassays of varying quality exist. Therefore, we decided to develop and validate a precise method for quantification of INSL3 by mass spectrometry.
\end{abstract}

Methods: We developed an assay in which the INSL3 A-chain is released from the INSL3 A-B heterodimer by chemical reduction and alkylation. The alkylated INSL3 A-chain is quantitated by liquid chromatography-tandem mass spectrometry (LC-MS/MS), as substitute for serum INSL3. The method was compared to a validated and sensitive in-house serum INSL3 immunoassay using 97 serum samples from 12 healthy boys during pubertal transition. Adult levels were determined based on sera from 72 adult healthy males aged 18-40 years.

Results: An LC-MS/MS assay with limit of detection and limit of quantification (LOQ) of 0.06 and $0.15 \mathrm{ng} / \mathrm{mL}$, respectively, and intra-assay $\mathrm{CVs}<9 \%$ in the relevant

\footnotetext{
*Corresponding author: Jakob Albrethsen, Department of Growth and Reproduction, Rigshospitalet, University of Copenhagen, Copenhagen, Denmark; and Reprounion and International Center for Research and Research Training in Endocrine Disruption of Male Reproduction and Child Health (EDMaRC), Rigshospitalet, University of Copenhagen, Section 5064, Rigshospitalet, Blegdamsvej 9, 2100, Copenhagen, Denmark, Phone: (+45) 3545 5085,

E-mail: Jakob.christian.albrethsen@regionh.dk.

http://orcid.org/0000-0002-2842-1128

Hanne Frederiksen, Anna-Maria Andersson, Loa Nordkap, Anne Kirstine Bang, Niels Jørgensen and Anders Juul: Department of Growth and Reproduction, Rigshospitalet, University of Copenhagen, Copenhagen, Denmark; and Reprounion and International Center for Research and Research Training in Endocrine Disruption of Male Reproduction and Child Health (EDMaRC), Rigshospitalet, University of Copenhagen, Copenhagen, Denmark

Ravinder Anand-Ivell: School of Biosciences, University of Nottingham, Nottingham, UK
}

ranges was obtained. The LC-MS/MS compared well with the in-house immunoassay (Deming regression slope: 1.28; Pearson correlation: $\mathrm{R}=0.86$ ). INSL3 concentrations increased with pubertal maturation in healthy boys. INSL3 concentrations were above the LOQ in all samples from the adult men. The mean ( $\pm 2 \mathrm{SD}$ range) for serum INSL3 concentrations in the adult men was $2.2(0.5-3.9) \mathrm{ng} / \mathrm{mL}$.

Conclusions: We have developed a robust and sensitive method suitable for quantitation of serum INSL3 in a clinical setting using LC-MS/MS instrumentation available in modern clinical laboratories. The method paves the way for future studies into the clinical role of serum INSL3 measurements.

Keywords: assay development; insulin-like factor 3 (INSL3); mass spectrometry.

\section{Introduction}

Insulin-like factor 3 (INSL3) is a 6.6-kDa peptide hormone and member of the insulin family [1]. In men, the testicular Leydig cells are the major, if not the only, source of INSL3, and measurement of circulating levels of INSL3 shows promise in the diagnostic evaluation of male subjects with andrological and developmental disorders [2]. Testosterone (T), the other major secretory product of the Leydig cells, is traditionally used as a biomarker for Leydig cell function and male hypogonadism. However, regulation of $\mathrm{T}$ is complex, and circulating $\mathrm{T}$ levels are influenced not only by testicular function but also by lifestyle (obesity, muscle mass, marital status, etc.), by hypothalamic and pituitary control and feedback and by metabolism, breakdown and interaction with binding proteins [3]. By contrast, INSL3 secretion is less influenced by other factors and is considered to directly reflect Leydig cell maturation and function [3]. INSL3 therefore has the potential to be a stable serum marker of Leydig cell function. In particular, serum INSL3 measurements could be clinically important in men with suspected hypogonadotropic hypogonadism. 
Furthermore, INSL3 measurements are needed during T treatment to evaluate Leydig cell maturation and function, as T measurements reflect endogenous as well as exogenous T. Serum INSL3 may also be useful in boys with puberty delay to distinguish between constitutional delay and hypogonadotropic hypogonadism [1, 2]. Diagnostic implementation of serum INSL3 as a routine clinical biomarker in the andrological workup has been hampered by the lack of commercially available and reliable INSL3 assays [2]. In this study, we present an in-house liquid chromatography-tandem mass spectrometry (LC-MS/ MS) method suitable for the large-scale studies needed to determine the clinical role of serum INSL3 measurements.

LC-MS/MS has become a standard method in clinical chemistry for the quantitation of small molecule analytes, such as steroids [4]. There is strong interest in expanding the clinical role of MS to include circulating proteins and peptides. However, due to the large dynamic range of the plasma proteome [5], the detection limit of MS-based plasma proteomics is typically $1-10 \mathrm{ng} / \mathrm{mL}$, and thus above the physiological range of many diagnostic proteins, including most peptide hormones. The level of serum INSL3 in adult males is typically $0.5-2 \mathrm{ng} / \mathrm{mL}$ [6], and to our knowledge, INSL3 has not previously been detected in serum/plasma by MS, including highly sensitive plasma proteomics (i.e. human plasma proteome) [7]. Alternatively, using a variety of "non-proteomics methods", MS has in a few cases successfully quantitated plasma peptides as low as the $\mathrm{pg} / \mathrm{mL}$ range [8]. The mature form of INSL3 was originally purified from bovine testicular tissue and was characterized as an A-B heterodimer that could be separated by chemical reduction of the disulfide bridges after which the A- and B-chains were detected by matrix-assisted laser desorption ionization-time of flight mass spectrometry (MALDI-TOF MS) [9]. The smaller A- and B-chains are likely better suited for LC-MS/MS analysis than the intact INSL3 A-B heterodimer. Here we develop and validate a robust and sensitive method whereby the human INSL3 A-chain is released from the INSL3 A-B heterodimer by reduction and alkylation and quantitated in serum by LC-MS/MS.

\section{Materials and methods}

\section{Serum samples}

The serum samples $(\mathrm{n}=97)$ from 12 healthy Danish boys (9-15 years old) were from a longitudinal substudy of the COPENHAGEN puberty study approved by the Danish Data Protection Agency (2015-41-4494) and by the Ethics Committee (KF 01 282,214 and V200.1996/90). For these boys, INSL3 levels measured by a non-commercial in-house immunoassay have previously been published [10]. The serum samples $(n=72)$ from adult healthy Danish men (18-40 years old) were from a study of testicular function approved by the Ethical board of the Danish Capital Region (permit number H-2-2012.092) [11]. Serum was collected and pooled from volunteering healthy males $(n=3$, age: $35-55$ years) and females ( $n=3$, age: $55-65)$ at Rigshospitalet for use in assay development.

\section{Chemicals}

Proteins were reduced with dithiothreitol (DTT) (Sigma Aldrich, Denmark) and alkylated using iodoacetamide (IAM) (Sigma). Lys-C/ trypsin (Promega, Denmark) was used for protein digestion. Milli- $\mathrm{Q}$ water was from a Millipore Synthesis A10 system (Billerica, MA, USA). All chemicals (ammonium biocarbonate $\left[\mathrm{NH}_{4} \mathrm{HCO}_{3}\right]$, ammonium acetate $\left[\mathrm{NH}_{4} \mathrm{AC}\right]$, ethanol [EtOH], acetonitrile [ACN], formic acid [FA] and tri-flouro acetic acid [TFA]) were of laboratory grade. Human recombinant IGF1, IGF2, insulin and bilirubin were from Sigma. Intralipid was from Fresenius Kabi (Copenhagen, Denmark).

\section{Calibrant and internal standard}

Lyophilized and recombinant human INSL3 (50 $\mu \mathrm{g}$, R\&D Systems, Abingdon, UK, bottled 12/15/2014) was dissolved in water:acetonitrile (95:5 v/v) and quantitated by triplicate amino acid analysis on a BioChrom 30 system (Alphalyse A/S, Odense, Denmark). The INSL3 stock was diluted in female serum and calibrants, and quality control (QC1-3) samples were stored at $-20^{\circ} \mathrm{C}$. Lyophilized synthetic INSL3 A-chain peptide was labeled at prolines 6 and $25\left({ }^{13} \mathrm{C}_{6},{ }^{15} \mathrm{~N}\right)$, and arginine $8\left({ }^{13} \mathrm{C}_{6},{ }^{15} \mathrm{~N}_{4}\right)$ (Pepscan, The Netherlands) was dissolved in water:acetonitrile (95:5 v/v) and used as internal standard (IS).

\section{Sample preparation}

The sample reagent $(100 \mathrm{~mL})$ was prepared daily by mixing $15 \mathrm{~mL}$ of 1.5 $\mathrm{M} \mathrm{NH}_{4} \mathrm{AC}, \mathrm{pH}$ : 8.6 with $85 \mathrm{~mL}$ of EtOH and spiked with IS. Serum, calibrant and QC samples $(150 \mu \mathrm{L})$ were transferred to tubes (LoBind, Eppendorf), sample reagent was added $(350 \mu \mathrm{L})$ and the samples were mixed $(600 \times g$ for $10 \mathrm{~s}$ and $100 \times g$ for $10 \mathrm{~min})$ and left at $-20^{\circ} \mathrm{C}$ for $1 \mathrm{~h}$ and centrifuged $\left(12.700 \times \mathrm{g}, 10 \mathrm{~min}, 4^{\circ} \mathrm{C}\right)$. The supernatant $(400 \mu \mathrm{L})$ was collected and reduced by addition of $5 \mu \mathrm{L}$ DTT (final conc. $1 \mu \mathrm{M}$ ) and left in shaker for $30 \mathrm{~min}\left(100 \times \mathrm{g}, 60^{\circ} \mathrm{C}\right)$. Alkylation was carried out by addition of $5 \mu \mathrm{L}$ IAM (final conc. $2 \mu \mathrm{M}$ ), and the samples were left in the dark for $30 \mathrm{~min}$ (room temperature). Subsequently, the samples were evaporated using nitrogen flow $\left(45^{\circ} \mathrm{C}, 90 \mathrm{~min}\right)$. The dried pellet was dissolved in $90 \mu \mathrm{L} 50 \mathrm{mM} \mathrm{NH}_{4} \mathrm{HCO}_{3}(\mathrm{pH} 8)$ and placed in a shaker for $5 \min \left(100 \times g, 60^{\circ} \mathrm{C}\right)$ and centrifuged $\left(12.700 \times \mathrm{g}, 10 \mathrm{~min}, 4^{\circ} \mathrm{C}\right)$. The supernatant $(80 \mu \mathrm{L})$ was transferred to vials.

\section{LC-MS/MS of serum INSL3}

Samples were kept at $10^{\circ} \mathrm{C}$ and injected $(65 \mu \mathrm{L})$ using an HTS PAL autosampler (CTC Analytics AG, Switzerland). LC-MS/MS analysis 
was performed on a Dionex UltiMate 3000 UHPLC system with integrated Transcend TLX TurboFlow coupled to a triple quadrupole mass spectrometer (TSQ Vantage, Thermo Scientific, USA) controlled by Aria MX 2.1 and Xcalibur 3.0.63 software (ThermoFinnigan, USA). The turboflow column was Cyclone-P Turboflow (proprietary stationary phase, $50 \mathrm{~mm} \times 0.5 \mathrm{~mm}$, Thermo) kept at $25^{\circ} \mathrm{C}$, and the analytical reverse phase-column was Kinetex (reverse phase C18, $50 \mathrm{~mm} \times 2.1 \mathrm{~mm}, 2.6 \mu \mathrm{M}, 100 \AA$ A , Phenomenex) with Security Guard Ultra (reverse phase C18 filter, $2.1 \mathrm{~mm} \times 4 \mathrm{~mm}, 2.6 \mu \mathrm{M}$ Phenomemex) kept at $45^{\circ} \mathrm{C}$. Eluent A was $0.2 \%$ FA in MQ water, and eluent B was $100 \% \mathrm{ACN}$. The total runtime was 10.1 min with a solvent flow on the eluting side of $0.3 \mathrm{~mL} / \mathrm{min}$, and the gradient increased from $12 \%$ to $50 \%$ solvent B. See Supplemental Figure 1 for details about the LC method. The MS instrument was equipped with a heated electrospray ionization probe operated in positive mode. The spray voltage was $3500 \mathrm{~V}$. Nitrogen was used as sheath gas, aux gas and sweep gas at 45, 40 and 0 (arbitrary units), respectively. The ion transfer tube was kept at $350^{\circ} \mathrm{C}$, and the vaporizer temperature was $425^{\circ} \mathrm{C}$. A cycle time of $0.2 \mathrm{~s}$ was used, and resolution (FWHM) at both Q1 and Q3 was 0.7. Argon was used as collision gas at a pressure of 2 mTorr and Chrom filter $=3$. Collision energies were $25 \mathrm{~V}$ and $30 \mathrm{~V}$, and s-lens settings were 150 and 160 for transitions 1 (T1) and 2 (T2), respectively.

\section{Validation experiments}

Several method parameters were determined according to CLSI guidelines [8]. To evaluate linearity, INSL3 was spiked in female serum pool. Nine concentrations were analyzed in triplicates, and the linearity of two INSL3 transitions was assessed: T1 (Q1:1002.8, Q3: 439.1 [y3+1]) and T2 (Q1:1002.8, Q3: $279.1[\mathrm{y} 2+1])$. Assay selectivity was evaluated by spiking human serum with members of the insulin family of peptides and with intralipid $(0,5,10,15$ and $20 \mathrm{mM})$ (to imitate samples with elevated triglycerides) or with bilirubin (0, $50,100,150,200$ and $300 \mathrm{mM}$ ) (to imitate samples with Icterus). Limit of detection (LOD) and limit of quantification (LOQ) were determined in female serum spiked with INSL3 to produce standard curves of five points (0.0, 0.1, 0.15, 0.2, 0.25 and $0.3 \mathrm{ng} / \mathrm{mL})$. LOD was defined as $4 \times \mathrm{SD}$ from the average zero concentration. LOQ was defined as the lowest concentration level where the results of five measurements resulted in a deviation below $20 \%$. The TurboFlow LC-MS/MS method was compared to a non-commercial time-resolved fluorescence immunoassay (TRFIA) by comparing the results obtained in 97 serum samples collected from 12 boys during pubertal transition (9-14 years), which previously had been analyzed by the TRFIA [10] and since stored at $-80^{\circ} \mathrm{C}$ for 3 years. Serum INSL3 was also measured in samples collected from 72 healthy adult men (age 18-40). The serum from healthy boys and adult men ( $\mathrm{n}=169$ samples) was previously analyzed for T and luteinizing hormone (LH) [10, 11]. Currently, there is no available certified reference material for INSL3, and three QC samples (0.25, 1.0 and $3.0 \mathrm{ng} / \mathrm{mL}$, respectively) were prepared inhouse by spiking female serum pool with recombinant INSL3. The QC samples were analyzed five times in one batch, and three times in each of five batches. Stability of serum INSL3 was assessed in serum stored for up to 3 days at $4^{\circ} \mathrm{C}$ or $27^{\circ} \mathrm{C}$. Samples were exposed to four cycles of freezing and storage $\left(24 \mathrm{~h}\right.$ at $\left.-20^{\circ} \mathrm{C}\right)$. The matrix effect was assessed by diluting the male serum pool $(2.5 \mathrm{ng} / \mathrm{mL})$ with pooled female serum from 2.5 to $0.125 \mathrm{ng} / \mathrm{mL}$ and, secondly, by spiking a pool of female serum with increasing amounts of recombinant INSL3 from 0.1 to $5.0 \mathrm{ng} / \mathrm{mL}$. Recovery was further examined in 10 serum samples from healthy boys with endogenous INSL3 of $0.15-0.3 \mathrm{ng} / \mathrm{mL}$ that were spiked with recombinant INSL3 corresponding to additional 1.0 or $5.0 \mathrm{ng} / \mathrm{mL}$.

\section{MALDI-TOF MS and Q-TOF MS of recombinant INSL3}

Proteins were treated by solid-phase extraction (zip-tips, C-4, Millipore) before MALDI-TOF MS (Autoflex, Bruker, Bremen, Germany). NanoLC-Q-TOF MS was performed on an Ultimate 3000 nano-LC system (Thermo) coupled to a MicrO-TOF QII MS instrument (Bruker). Peptides were trapped on a C18 precolumn (300 $\mu \mathrm{m}$ inner diameter $\times 5 \mathrm{~mm}$; Dionex) with a flow rate of $20 \mu \mathrm{L} / \mathrm{min}$ solvent $\mathrm{C}(1 \% \mathrm{ACN}, 0.1 \% \mathrm{TFA})$ for $10 \mathrm{~min}$ and switched online with the analytical C18 column $(75 \mu \mathrm{m}$ inner diameter $\times 50 \mathrm{~cm}$; PepMap C18, Dionex), and eluted with flow rate $200 \mathrm{~nL} / \mathrm{min}$ and a gradient of 4\%-90\% solvent B over 30 min (solvent A: $0.1 \%$ FA; solvent B: $0.1 \%$ FA, 80\% ACN). Region $m / z$ 100-2500 was collected for MS1 analysis. Distiller software (Mascot V2.5.1, UK) was used for peak processing and database search in the Swiss Prot Database with oxidation of methionine as variable modification and no proteolytic digestion. The precursor and fragment mass deviations were $60 \mathrm{ppm}$ and $0.1 \mathrm{Da}$, respectively, with FDR $<1 \%$.

\section{Statistics}

Descriptive analyses (R, Deming regressionn and Pearson correlation) were performed using Excel 2010 (Microsoft). See details in Supplemental Table 1.

\section{Results}

\section{Assay development}

MALDI-TOF MS of recombinant INSL3 identified a mass peak of $m / z 6785.9$, in agreement ( $>99.9 \%$ ) with the mass of the human INSL3 A-B heterodimer (theoretical MW 6786.9 Da) (Figure 1A). Reduction and alkylation resulted in the disappearance of the signal from intact INSL3 and emergence of three mass peaks (Figure 1B). The mass peaks of $\mathrm{m} / \mathrm{z} 3006.3$ and 4130.2 correspond well (>99.9\%) with the MWs of the alkylated A- and B-chains (theoretical MW 3005.3 and 4129.7 Da, respectively) (Figure 1B). We have no explanation for the emergence of the MALDI-TOF MS mass peak with $m / z 2945.3$ (Figure 1B). The sequence of the recombinant alkylated INSL3 A-chain was verified by nanoLC-Q-TOF MS (Figure 1C). Database search (Blast and Uniprot) revealed that the sequence of human INSL3 A-chain is unique and contains no known posttranslational modifications. Next, combinations of the alkylated INSL3 A-chain (in charge states from +3 to +6 ) and the theoretical $\mathrm{B}$ and $\mathrm{Y}$ product ions (charge states 

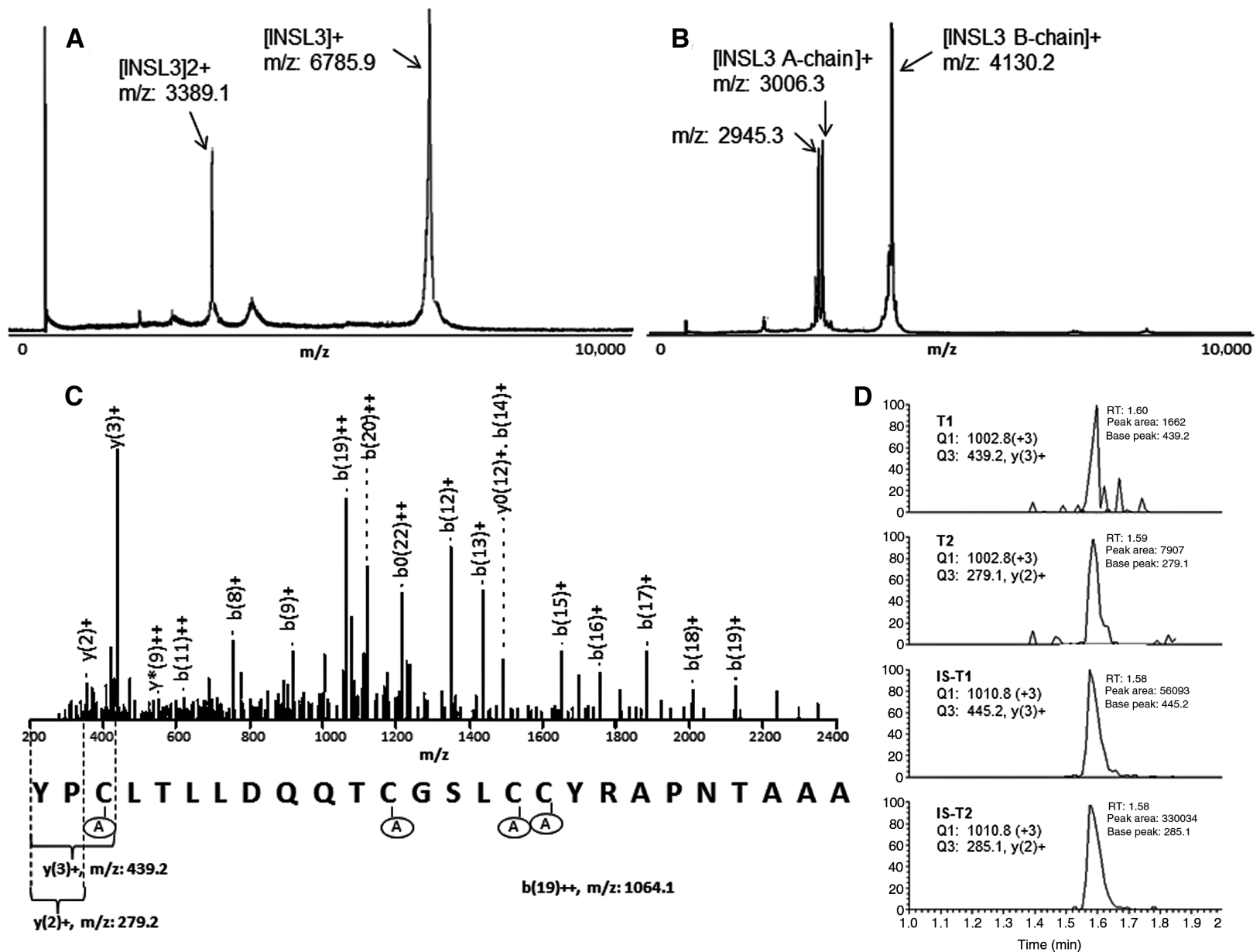

Figure 1: Identification of LC-MS/MS transitions for serum INSL3.

MALDI-TOF MS analysis of the intact INSL3 A-B heterodimer (A), and of the individual INSL3 A- and B-chains after reduction and alkylation (B). NanoLC-Q-TOF MS of the alkylated INSL3 A-chain (C). TurboFlow LC-MS/MS of serum INSL3 $(1.0 \mathrm{ng} / \mathrm{mL})$ and internal standard peptide spiked in human serum, using transitions 1 and 2 (D).

$+1,+2$ and +3 ) were tested on high throughput TurboFlow LC-MS/MS (see Supplemental Figure 2). Two transitions of the triple-charged and alkylated INSL3 A-chain performed best and are subsequently referred to as T1 (Q1:1002.8, Q3: 439.1 [y3+1]) and T2 (Q1:1002.8, Q3: 279.1 [y2+1]). An overview of the analytical strategy is provided in Supplemental Figure 3. Due to its low abundance, we were not able to detect INSL3 in human serum using proteomics methods (Supplemental Figure 4).

\section{Selectivity}

A synthetic and stable isotope-labeled human INSL3 A-chain was used for IS (Supplemental Figure 5), and the IS co-eluted with INSL3 detected in pooled serum from males (Figure 1D). No signal for T1 or T2 was observed when measuring pooled female serum (Supplemental
Figure 6A), as is expected because serum INSL3 is often low, or undetectable, in female serum $(<0.01 \mathrm{ng} / \mathrm{mL})$. Second a signal was observed for both $\mathrm{T} 1$ and $\mathrm{T} 2$ when measuring female serum spiked with INSL3, but not after spiking with other related peptides (Supplemental Figure 6B-E) and only after both reduction and alkylation (data not shown). Together these observations support that the assay selectively detects the alkylated INSL3 A-chain after release from the recombinant or endogenous INSL3 A-B heterodimer.

\section{Sensitivity}

The method was validated in accordance with CLSI guidelines for LC-MS/MS assays [8]. First, the stock solution of recombinant human INSL3 was quantitated by amino-acid analysis (Supplemental Figure 7), and good 
Table 1: Validation of Turboflow LC-MS/MS of serum insulin-like factor 3 (INSL3).

\begin{tabular}{lr}
\hline LOD, ng/mL & 0.06 \\
LOQ, ng/mL & 0.15 \\
Linear range, ng/mL & $0.15-5.0$ \\
Intra-assay CV, \% & $5.4-8.8$ \\
Inter-assay CV, \% & $11.7-14.5$ \\
Recovery, \% & $87-130$ \\
\hline
\end{tabular}

linearity of calibration curves was obtained by monitoring $\mathrm{T} 1$ and $\mathrm{T} 2$. There was no significant difference $(\mathrm{p}>0.98$, t-test, two-sided), or systematic difference (residual plot), between linear and higher-order polynomial fitting in the range from 0.15 to $5.0 \mathrm{ng} / \mathrm{mL}$ (Supplemental Figure 8). LOD and LOQ were respectively 0.14 and $0.25 \mathrm{ng} / \mathrm{mL}$ (ave. $\mathrm{S} / \mathrm{N}$ : 134) for $\mathrm{T} 1$, and 0.06 and $0.15 \mathrm{ng} / \mathrm{mL}$ (ave. S/N: 68) for T2 (Table 1) (Supplemental Figure 9A). Accordingly, $\mathrm{T} 2$ was chosen for quantitation, whereas as $\mathrm{T} 1$ was used as qualifier transition for INSL3 measurements. The method was only validated in human serum, but endogenous INSL3 was detected in plasma (Supplemental Figure 9B).

\section{Method comparison}

The results from TurboFlow LC-MS/MS of 97 serum samples were compared to a non-commercial TRFIA [10]. All 97 samples contained sufficient INSL3 levels to be measured by the TRFIA (LOQ: $0.01 \mathrm{ng} / \mathrm{mL}, \mathrm{CV}<10 \%$ ) $[6,10,12]$. Scatterplot of LC-MS/MS vs. TRFIA in all 97 samples is shown in Supplemental Figure 10A. According to TRFIA, 30 samples contained INSL3 levels below the LOQ $(0.15 \mathrm{ng} / \mathrm{mL})$ of the LC-MS/MS method. For the
67 samples with INSL3 $>0.15 \mathrm{ng} / \mathrm{mL}$, the Deming regression slope was 1.28 , the Pearson correlation was $R=0.86$ (Figure 2A and Supplemental Table 1) and two of the 67 samples deviated more than 1.96 times the standard deviation in a difference plot (Figure 2B). Of the remaining 30 samples, 26 contained less than the LOQ when measured by the LC-MS/MS method. In four samples (containing $0.03,0.12,0.09$ and $0.14 \mathrm{ng} / \mathrm{mL}$, respectively, according to TRFIA), the concentration of INSL3 was slightly above the LOQ with LC-MS/MS (0.2, $0.2,0.25$ and $0.3 \mathrm{ng} / \mathrm{mL}$, respectively) (Supplemental Figure 10B).

\section{INSL3 as a marker of Leydig cell functionality}

The mean serum INSL3 was $2.2 \mathrm{ng} / \mathrm{mL} \quad(\mathrm{SD}=0.8)$ in 72 healthy males giving a 95\% confidence range $( \pm 1.96 \times \mathrm{SD})$ of $0.5-3.9 \mathrm{ng} / \mathrm{mL}$ (Figure $2 \mathrm{C})$. There was no significant difference between INSL3 levels in the young $(\mathrm{n}=32$, age: $18-20$ years) and middle-aged $(\mathrm{n}=40$, age: 21-40 years) subgroups of men (t-test for means, twosided, $\mathrm{p}=0.19$ ). In the boys, pubertal onset was defined as testicular volume $>3 \mathrm{~mL}$, and testicular volume increased with age [10]. INSL3, LH and T appeared to increase simultaneously during pubertal transition in healthy males (Figure 3A-C).

\section{Additional assay validation}

The intra-assay (15 measurements) and inter-assay (45 measurements) CVs were below $<15 \%$ (Table 1). Intralipid and bilirubin showed with no significant impact on serum
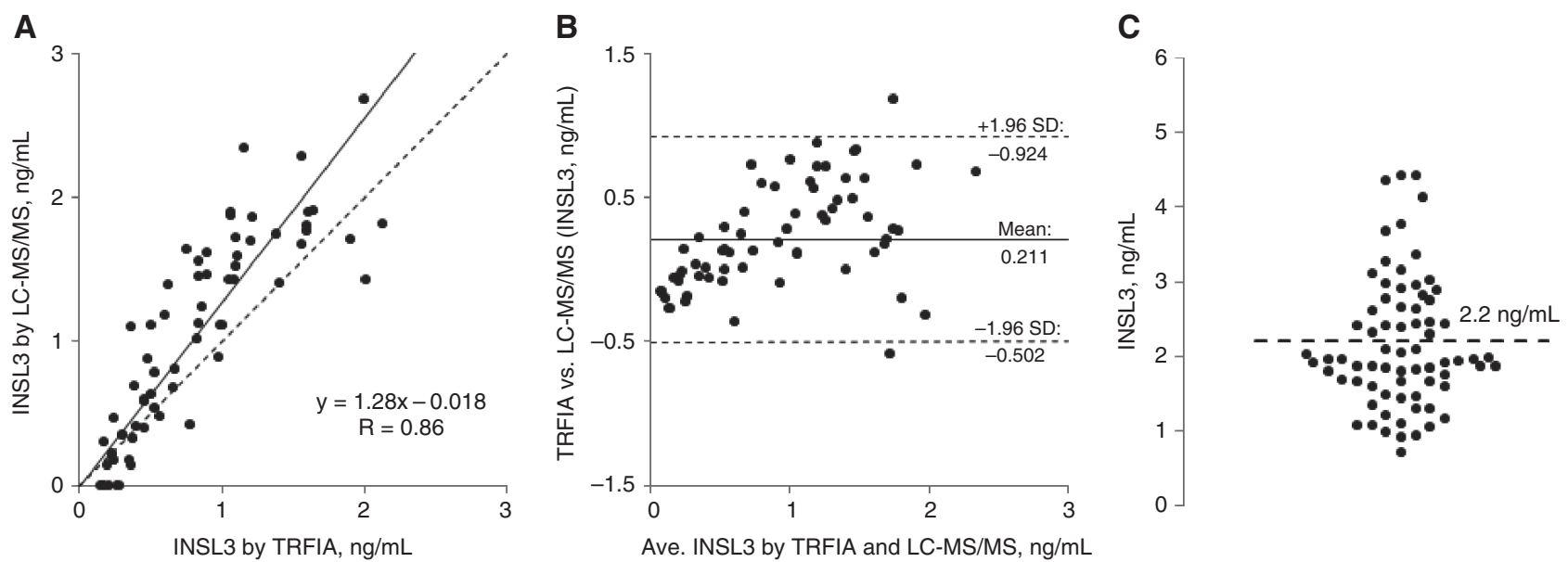

Figure 2: LC-MS/MS of serum INSL3.

Comparison of TRFIA and Turboflow LC-MS/MS-based quantitation of serum INSL3 ( $n=67)$ shown as scatterplot $(A)$ and difference plot (B).

Turboflow LC-MS/MS of serum INSL3 from healthy adult males $(n=72)(C)$. 

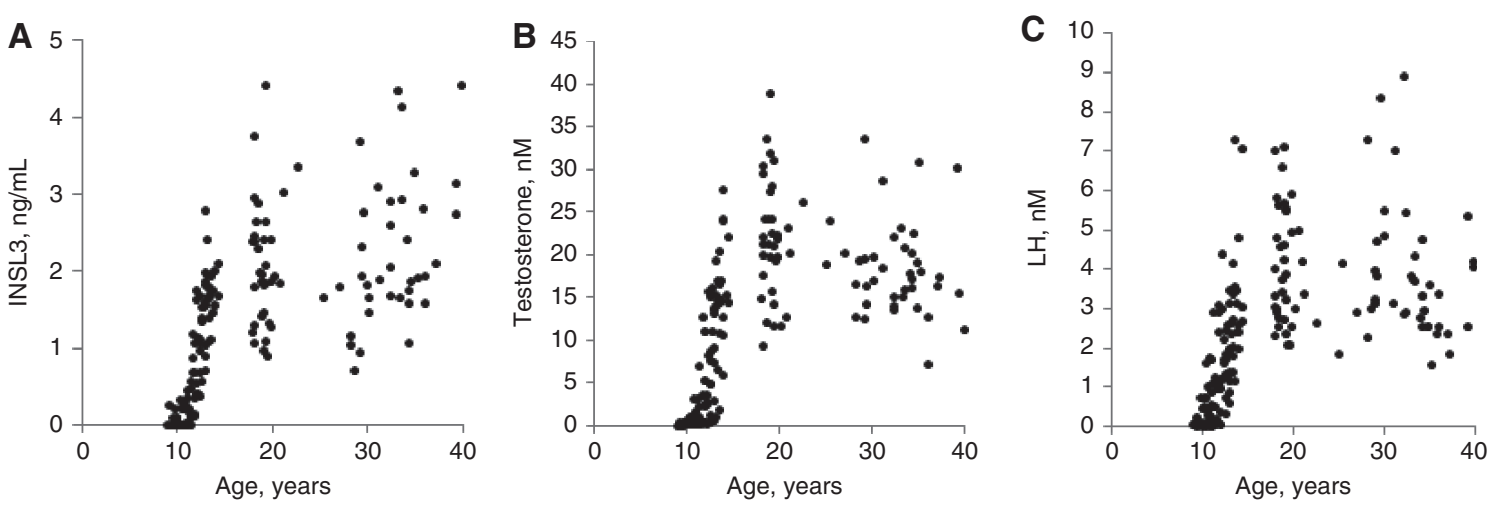

Figure 3: Change of serum INSL3, testosterone and LH with age.

TurboFlow LC-MS/MS of serum INSL3 in males (age 9-40 years, $n=169)(A)$, compared to previously measured Ref. [10, 11] testosterone and LH in the same samples (B and C).

INSL3 (Supplemental Figure 11). Although INSL3 seemed to decrease slightly after 2 days storage at $27^{\circ} \mathrm{C}$, this was non-significant (Supplemental Figure 12), and there was no effect from freezing and thawing. Spiking and dilution curves were linear $\left(R^{2}>0.98\right)$ with almost similar slopes (Supplemental Figure 13), and the recovery was 87\%-130\% (Table 1). There was no carryover observed on both T1 or T2 in subsequent blank measurement when female serum was spiked with $20 \mathrm{ng} / \mathrm{mL}$ INSL3 (data not shown). As QC, there was good correlation for the results obtained by monitoring the qualifier (T1) and the quantifier (T2) transition $\left(\mathrm{R}^{2}>0.86\right)$ in the 72 adult men (Supplemental Figure 14).

\section{Discussion}

We present a robust and sensitive LC-MS/MS-based method whereby the alkylated INSL3 A-chain is quantitated in serum, as surrogate for the INSL3 A-B heterodimer. The assay sensitivity is well suited for serum INSL3 measurements in adult males $(\mathrm{LOQ}=0.15 \mathrm{ng} / \mathrm{mL})$. The reproducibility of the method was $<15 \%$, and the presented in-house method can be performed on LC-MS/MS instruments available in hospital laboratories (i.e. UHPLC coupled with Triple-Q MS). The workload is only slightly higher as compared to the in-house LC-MS/MS-based method we use for routine measurements of androgens [13]. We hypothesize that INSL3 determination will improve existing diagnostic procedures for male patients with suspected hypogonadotropic hypogonadism. As a next step, the biological variation of serum INSL3 should be examined in a large number of healthy males. Studies should also be performed to describe the dynamic relationship between serum INSL3 and other hormones in testicular disorders and puberty. The receptor for INSL3, relaxin family peptide receptor 2 (RXFP2), is widely expressed, and INSL3 may be important for germ cell stability [14] and bone metabolism [15]. Future studies may unravel additional endocrine roles of INSL3.

The results obtained with this newly developed LC-MS/MS method correlate well to those obtained with a non-commercial TRFIA. The TRFIA has been optimized for improved sensitivity $[6,10,12]$ and was successfully applied in several studies, including a study of a large serum cohort from adult males [6] and for sensitive analysis of low levels of INSL3 in women serum [12]. According to both LC-MS/MS and TRFIA, serum INSL3 increased in healthy boys during pubertal transition. Overall, slightly higher serum INSL3 levels were obtained with the LC-MS/MS-based method, and second, the two methods appeared to deviate relatively more in the high concentration range, although only two measurements fell outside the $1.96 \mathrm{SD}$ limits in a difference plot. For optimal method comparison with the TRFIA, we used the same recombinant INSL3 peptide spiked in a similar matrix (pool of serum from women) as calibration solution, and the stock solution of INSL3 peptide was accurately quantitated by amino acid analysis. We propose that the bias in measured levels between the LC-MS/MS and the TRFIA method could be due to either the preparation of the calibrants or the structural changes of INSL3 during sample processing that may influence detection by either assay (dilution, storage, etc.). After the TRFIA analysis, the serum was stored for 3 years at $-80^{\circ} \mathrm{C}$ before LC-MS/ MS analysis, but this probably does not explain the slightly higher values obtained in the later measurement. Recombinant standard protein and synthetic ISs may contain minor contaminants, but these are unlikely to interfere with assay quantitation in LC-MS/MS. The 
average serum INSL3 in our 72 healthy adult Danish men was $2.2 \mathrm{ng} / \mathrm{mL}$ (0.5-3.9). In another study, using TRFIA, the average level measured in healthy adult males (aged 35-44 years) was $1.3 \mathrm{ng} / \mathrm{mL}(0.3-3.5)$, and declined with age [6]. Two other studies using TRFIA reported averages of $0.9-0.99 \mathrm{ng} / \mathrm{mL}$ in adult healthy men $[16,17]$. In addition to differences associated with calibration and methods, the differences in average INSL3 observed in healthy men with LC-MS/MS and TRFIA could reflect cohort differences. According to a commercial ELISA, the average was $1.5 \mathrm{ng} / \mathrm{mL}$ in healthy males [18] and $2.7 \mathrm{ng} / \mathrm{mL}$ in patients with Klinefelter syndrome [19], whereas the commercial RIA measures up to 10 -fold lower levels of serum INSL3 than the other three assays [20-22]. Thus, discrepancies exist using the commercially available assays. In the future, reference material for INSL3 should be developed for interlaboratory comparisons, and a matrix of organic solution (i.e. 20\% ACN) may be more practical for calibration. It remains to be seen whether the LC-MS/MS method is sufficiently sensitive for detection of earliest stages of male puberty. In boys, serum INSL3 increased dramatically at the onset of puberty, but it cannot be excluded that in some boys serum INSL3 may be present $\angle$ LOD at the earliest stage of puberty. Interestingly, LC-MS/MS of INSL3 may demonstrate better analytical sensitivity in plasma as compared to serum (Supplementary Figure 9A).

Serum INSL3 was quantitated by LC-MS/MS using the triple-charged and alkylated INSL3 A-chain as precursor. A C-terminal product ion $(\mathrm{y} 2[+1], m / z 279.1)$ provided best sensitivity and results from proline-directed fragmentation [23] and is predicted to provide a particularly strong signal [24]. The presented analytical principle may be applicable to other members of the insulin-like family of peptides and to their therapeutic analogues [25]. In comparison, LC-MS/MS-based quantitation of human insulin is also possible by using C-terminal fragments as product ions, but from the B-chain [26]. The alkylated INSL3 B-chain was detected by MALDI-TOF MS, but not by LC-MS/MS, probably due to the extreme hydrophobicity (pI: 9.6) of the B-chain resulting in low solubility and poor LC separation. In a previous study, reduction of INSL3 from bovine testicular tissue produced two forms of the INSL3 B-chain possibly due to alternative $\mathrm{N}$-terminal cleavage, whereas the A-chain was identified in a single form only [9], and thus, the A-chain could be the better target for quantitation of INSL3 by LC-MS/MS. We believe that INSL3 is fully denatured after $30 \mathrm{~min}$ at $60^{\circ} \mathrm{C}$ in $80 \%$ ethanol, and thus, all cysteines will therefore be exposed for reduction, but this requires further investigation. Future studies should also examine using stable isotope-labeled and recombinant INSL3 protein, or recombinant INSL3 from another species, as IS as this may allow for further compensation of potential assay variation associated with reduction of INSL3 and other analytical steps. The selectivity of the LC-MS/ MS method was demonstrated by showing no signal in samples spiked with other recombinant proteins belonging to the insulin-like hormone superfamily. Furthermore, 30 serum samples that according to the TRFIA contained INSL3 below the LOQ $(<0.15 \mathrm{ng} / \mathrm{mL})$ were also in the LC-MS/MS confirmed as being below, or in four cases slightly above, the LOQ. It is possible that both the mature form of INSL3 $(6.6 \mathrm{kDa})$ and the pro-form(s) of INSL3 (12-14 kDa) are secreted from mammalian Leydig cells [1]. The available immunoassays recognize the correctly folded INSL3 B-chain that is present in all isoforms. The LC-MS/MS method instead measures the free INSL3 A-chain that can be released from the A-B heterodimer $(6.6 \mathrm{kDa})$ by breaking of disulfide bridges, but not from pro-INSL3 $(12-14 \mathrm{kDa})$ where the A-chain is linked to the C-domain by a peptide bond (see Supplemental Figure 3). The correlation between TRFIA and LC-MS/ MS measurements therefore support that in humans the majority, if not all, of the circulating INSL3 is present as the A-B heterodimer in agreement with the structure of INSL3 extracted from bovine testis [9]. Hypothetically, the A-chain could possibly also be released from another (unknown) structural form of endogenous INSL3.

In conclusion, INSL3 measurements could be clinically relevant for the detection of Leydig cell impairment in the heterogenous group of males with andrological disorders $[1,2]$. The presented method adds serum INSL3 to the panel of diagnostic male reproductive hormones ( $\mathrm{LH}$, follicle-stimulating hormone, $\mathrm{T}$, inhibin $\mathrm{B}$ and antiMüllerian hormone) that can be analyzed in large-scale studies. However, future studies will have to confirm the clinical role of serum INSL3 measurements.

Author contributions: All the authors have accepted responsibility for the entire content of this submitted manuscript and approved submission.

Research funding: Innovation Fund Denmark 14-2013-4; International Center for Research, and Research Training in Endocrine Disruption of Male Reproduction and Child Health (EDMaRC); ReproUnion.

Employment or leadership: None declared.

Honorarium: None declared.

Competing interests: The funding organization(s) played no role in the study design; in the collection, analysis, and interpretation of data; in the writing of the report; or in the decision to submit the report for publication. 


\section{References}

1. Ivell R, Anand-Ivell R. Biology of insulin-like factor 3 in human reproduction. Hum Reprod Update 2009;15:463-76.

2. Bay K, Andersson AM. Human testicular insulin-like factor 3: in relation to development, reproductive hormones and andrological disorders. Int J Androl 2011;34:97-109.

3. Ivell R, Anand-Ivell R. Biological role and clinical significance of insulin-like peptide 3. Curr Opin Endocrinol Diabetes Obes 2011;18:210-6.

4. Grebe SK, Singh RJ. LC-MS/MS in the clinical laboratory - where to from here? Clin Biochem Rev 2011;32:5-31.

5. Anderson NL, Anderson NG. The human plasma proteome: history, character, and diagnostic prospects. Mol Cell Proteomics 2002;1:845-67.

6. Anand-Ivell R, Wohlgemuth J, Haren MT, Hope PJ, Hatzinikolas G, Wittert G, et al. Peripheral INSL3 concentrations decline with age in a large population of Australian men. Int J Androl 2006;29:618-26.

7. Schwenk JM, Omenn GS, Sun Z, Campbell DS, Baker MS, Overall CM, et al. The human plasma proteome draft of 2017: building on the human plasma peptideAtlas from mass spectrometry and complementary assays. J Proteome Res 2017;16:4299-310.

8. Lynch KL. CLSI C62-A: a new standard for clinical mass spectrometry. Clin Chem 2016;62:24-9.

9. Büllesbach EE, Schwabe C. The primary structure and the disulfide links of the bovine relaxin-like factor (RLF). Biochemistry 2002;41:274-81.

10. Johansen ML, Anand-Ivell R, Mouritsen A, Hagen CP, Mieritz MG, Søeborg T, et al. Serum levels of insulin-like factor 3, anti-Mullerian hormone, inhibin $\mathrm{B}$, and testosterone during pubertal transition in healthy boys: a longitudinal pilot study. Reproduction 2014;147:529-35.

11. Bang AK, Nordkap L, Almstrup K, Priskorn L, Petersen JH, Rajpert-De Meyts E, et al. Dynamic GnRH and hCG testing: establishment of new diagnostic reference levels. Eur J Endocrinol 2107;176:379-91.

12. Anand-Ivell R, Tremellen K, Dai Y, Heng K, Yoshida M, Knight PG, et al. Circulating insulin-like factor 3 (INSL3) in healthy and infertile women. Hum Reprod 2013;28:3093-102.

13. Søeborg T, Frederiksen H, Johannsen TH, Andersson AM, Juul A. Isotope-dilution TurboFlow-LC-MS/MS method for simultaneous quantification of ten steroid metabolites in serum. Clin Chim Acta 2017;468:180-6.

14. Kawamura K, Kumagai J, Sudo S, Chun SY, Pisarska M, Morita $\mathrm{H}$, et al. Paracrine regulation of mammalian oocyte maturation and male germ cell survival. Proc Natl Acad Sci USA 2004;101:7323-8.

15. Ferlin A, Pepe A, Gianesello L, Garolla A, Feng S, Giannini S, et al. Mutations in the insulin-like factor 3 receptor are associated with osteoporosis. J Bone Miner Res 2008;23:683-93.
16. Roth MY, Lin K, Bay K, Amory JK, Anawalt BD, Matsumoto AM, et al. Serum insulin-like factor 3 is highly correlated with intratesticular testosterone in normal men with acute, experimental gonadotropin deficiency stimulated with low-dose human chorionic gonadotropin: a randomized, controlled trial. Fertil Steril 2013;99:132-9.

17. Bay K, Hartung S, Ivell R, Schumacher M, Jürgensen D, Jorgensen $\mathrm{N}$, et al. Insulin-like factor 3 serum levels in 135 normal men and 85 men with testicular disorders: relationship to the luteinizing hormone-testosterone axis. J Clin Endocrinol Metab 2005;90:3410-8.

18. Ermetici F, Donadio F, Lorio L, Malavazos AE, Dolci A, Peverelli E, et al. Peripheral insulin-like factor 3 concentrations are reduced in men with type 2 diabetes mellitus: effect of glycemic control and visceral adiposity on Leydig cell function. Eur J Endocrinol 2009;161:853-9.

19. Rohayem J, Fricke R, Czeloth K, Mallidis C, Wistuba J, Krallmann C, et al. Age and markers of Leydig cell function, but not of Sertoli cell function predict the success of sperm retrieval in adolescents and adults with Klinefelter's syndrome. Andrology 2015;3:868-75.

20. Foresta C, Bettella A, Vinanzi C, Dabrilli P, Meriggiola MC, Garolla A, et al. A novel circulating hormone of testis origin in humans. J Clin Endocrinol Metab 2004;89:5952-8.

21. Trabado S, Maione L, Bry-Gauillard H, Affres H, Salenave S, Sarfati J, et al. Insulin-like peptide 3 (INSL3) in men with congenital hypogonadotropic hypogonadism/Kallmann syndrome and effects of different modalities of hormonal treatment: a single-center study of 281 patients. J Clin Endocrinol Metab 2014;99:E268-75.

22. Chang WH, Li SS, Wu MH, Pan HA, Lee CC. Phthalates might interfere with testicular function by reducing testosterone and insulin-like factor 3 levels. Hum Reprod 2015;30:2658-70.

23. Loo JA, Edmonds CG, Smith RD. Tandem mass spectrometry of very large molecules. 2. Dissociation of multiply charged proline-containing proteins from electrospray ionization. Anal Chem 1993;65:425-38

24. Degroeve S, Maddelein D, Martens L. MS2PIP prediction server: compute and visualize MS2 peak intensity predictions for CID and HCD fragmentation. Nucleic Acids Res 2015;43:W326-30.

25. Hossain MA, Wade JA. Novel methods for the chemical synthesis of insulin superfamily peptides and of analogues containing disulfide isosteres. Acc Chem Res 2017;50:2116-27.

26. Thevis M, Thomas A, Delahaut P, Bosseloir A, Schänzer W. Qualitative determination of synthetic analogues of insulin in human plasma by immunoaffinity purification and liquid chromatography-tandem mass spectrometry for doping control purposes. Anal Chem 2005;77:3579-85.

Supplemental Material: The online version of this article offers supplementary material (https://doi.org/10.1515/cclm-2018-0171). 